\title{
Provision of child and adolescent mental health in-patient services in England between 1999 and 2006
}

\author{
AIMS AND METHOD \\ In 1999, child and adolescent mental \\ health (CAMH) in-patient provision \\ was unevenly distributed across \\ England. A repeat of a 1999 bed count \\ survey was conducted in 2006 to \\ determine whether change had \\ occurred in response to government \\ policy.

\section{RESULTS} \\ Total bed numbers in England were \\ found to have increased by $284 ; 69 \%$ \\ of the increase is due to the indepen- \\ dent sector, whose market share has \\ risen from $25 \%$ in 1999 to $36 \%$ in \\ 2006. Regions with the highest \\ number of beds in 1999 have \\ increased bed numbers more than \\ areas with the lowest number of beds \\ in 1999 ( 8.3 v. 3.6 beds per million \\ population). In units that admit only \\ children under the age of 14 , there \\ has been a $30 \%$ reduction in beds \\ available (123 to 86).
}

\author{
CLINICAL IMPLICATIONS \\ Inequity in provision of CAMH in- \\ patient services has increased despite \\ government policy to the contrary. \\ We speculate that this might be \\ partly due to fragmented and local \\ commissioning, and the effects of \\ market forces operating as a result of \\ increasing privatisation.
}

A survey conducted in 1999 found that child and adolescent mental health (CAMH) in-patient units in England were unevenly distributed. This was largely due to a concentration of units managed by the independent sector in London and the south-east of England. It was suggested that this might create inequity of access, could adversely affect the care of those young people admitted to units distant from their home, and indicated the need for national planning of this scarce resource ( $\mathrm{O}^{\prime}$ Herlihy et al, 2003). Since the survey was undertaken, a National Service Framework has been published that sets out standards and milestones for achieving an equitable child and adolescent mental health service (Department of Health, 2004), and increased funding has been made available (Department of Health, 2002). This paper reports the change in $\mathrm{CAMH}$ in-patient provision between 1999 and 2006 and the effect of new investment on the evenness of its distribution.

\section{Method}

\section{Criteria for inclusion}

A unit is defined here as a hospital ward or other healthcare setting whose specialist function is to admit young people with a mental disorder. Thus a hospital or service may contain more than one unit. Units for young people with intellectual (learning) disability or substance misuse are only included if it is policy to admit those with a comorbid mental disorder. The survey covers both the National Health Service (NHS) and the independent sector. It excludes residential settings managed by local authorities and units managed by the independent sector whose main purpose is to provide social care or that admit young people solely for the purpose of detention.

\section{The survey}

We conducted the 1999 survey and have maintained direct contact with all CAMH in-patient units in England through their research and development activities. This network means that we are aware of any existing unit that closes and any new unit that is established. For the 2006 survey, a research worker interviewed the unit manager or lead clinician of each unit over the telephone to ascertain (a) the number of beds available for use, (b) the age group accepted for admission, (c) admission policy, and (d) the diagnostic groups treated.

Units can be categorised according to the age group of the young people admitted (children, adolescents or both) and to the types of problem of the young people admitted. Units that admit children and/or adolescents with a wide range of diagnoses and problems are categorised as 'general'. More information about the criteria used in this classification is given in the report of the 1999 survey (O'Herlihy et al, 2003).

\section{Results}

Between 1999 and 2006 the total number of units in England has risen from 72 to 91 and the number of beds provided by 284 (from 844 to 1128). Sixty-nine percent of the increase in bed numbers is a result of new beds opened by independent sector providers. Consequently the percentage of total bed provision managed by the independent sector has risen from 25 to $36 \%$.

Table 1 summarises the change between 1999 and 2006 in the number of CAMH beds by type and managing agency. There have been some changes in the overall balance of provision. The number of forensic and secure beds has increased greatly whereas the number of general beds in units that only admit children under age 14 has fallen. 
For the element of provision managed by the NHS, there has been new investment in forensic units and disinvestment from children's units. There has also been a change in emphasis for NHS managed general adolescent in-patient services. In 2006, a higher proportion of these beds (61 of $625,10 \%)$ are short-stay, with a target length of admission of between 6 and 8 weeks, than was the case in 1999 (10 of 459, 2\%).

The independent sector has increased its market share of eating disorder beds, from $75 \%$ to $82 \%$, and of general adolescent beds, from $15 \%$ to $27 \%$ (there were 71 such beds in 1999 and 169 in 2006), and has a virtual monopoly of secure psychiatric beds.

Table 2 shows the distribution of beds per 1 million of the total population across nine English regions, and the change in this between 1999 and 2006. The number of beds in the four regions with highest provision in 1999 (all four had more than 23 beds per million) has increased by a mean of 8.3 per million. In contrast, the number of beds in the five regions with the lowest provision (all five had fewer than 12 beds per million) has increased by 3.6 per million. Furthermore, nearly all of the increase for the most poorly provided areas is accounted for by a single English region, the West Midlands, which, following a strategic review in 2002, established a new short-stay general adolescent unit and an NHS forensic unit. At about the same time, a new independent sector unit also opened.

The distribution of types of specialist unit and age group catered for is also uneven. Eating disorder services are confined to four of the nine English regions, with four units in London accounting for 75 of the 113 beds (66\%). The 183 secure and forensic beds provided by 12 units are located in six regions.

Table 1. CAMH bed numbers and type managed by the NHS and the independent sector in England between 1999 and 2006

\begin{tabular}{|c|c|c|c|c|c|c|c|c|c|}
\hline & \multicolumn{3}{|c|}{ All beds } & \multicolumn{3}{|c|}{ NHS beds } & \multicolumn{3}{|c|}{ Independent sector beds } \\
\hline & 1999 & 2006 & $\begin{array}{c}\text { Change, } \\
\%\end{array}$ & 1999 & 2006 & $\begin{array}{c}\text { Change, } \\
\%\end{array}$ & 1999 & 2006 & $\begin{array}{c}\text { Change, } \\
\%\end{array}$ \\
\hline \multicolumn{10}{|l|}{ Unit type } \\
\hline General $^{1}$ & 620 & 739 & 19 & 549 & 570 & 4 & 71 & 169 & 138 \\
\hline Eating disorder & 73 & 113 & 55 & 18 & 20 & 11 & 55 & 93 & 69 \\
\hline Psychiatric forensic & 16 & 68 & 325 & 16 & 68 & 325 & 0 & 0 & 0 \\
\hline Psychiatric secure & 56 & 115 & 105 & 0 & 10 & - & 56 & 105 & 88 \\
\hline Learning disability & 79 & 93 & 18 & 49 & 53 & 8 & 30 & 40 & 33 \\
\hline \multicolumn{10}{|l|}{ Age group } \\
\hline Children only ( $<14$ years) & 123 & 86 & -30 & 123 & 86 & -30 & 0 & 0 & 0 \\
\hline Children and adolescents ( $4-16$ years $)^{2}$ & 50 & 104 & 108 & 50 & 48 & -4 & 0 & 56 & - \\
\hline Adolescents (12-18 years) & 671 & 938 & 40 & 459 & 587 & 28 & 212 & 351 & 66 \\
\hline
\end{tabular}

$\mathrm{CAMH}$, Child and adolescent mental health

1. General units include a child and adolescent unit for young people who are deaf, a general adolescent unit that specialises in treating young people who self-harm and a combined paediatric and psychiatric service.

2. The increase in beds for children and adolescents is accounted for by two eating disorder units managed by the independent sector. One is a new unit that admits those between the ages of 8 and 18. The other is an existing unit that reduced its lower admission age threshold in 2003.

Table 2. Total CAMH and general bed numbers per million population in English regions

\begin{tabular}{|c|c|c|c|c|c|}
\hline \multirow[b]{2}{*}{ Region $^{2}$} & \multicolumn{3}{|c|}{ Beds per million population, CAMH (general) ${ }^{1}$} & \multicolumn{2}{|c|}{$\begin{array}{l}\text { Total beds managed } \\
\text { by the independent sector, } \%\end{array}$} \\
\hline & 1999 & 2006 & Change, \% & 1999 & 2006 \\
\hline North East & $27.8(11.9)$ & $36.2(12.7)$ & $30(7)$ & 0 & 0 \\
\hline London & $26.5(19.5)$ & $44.2(28.6)$ & $67(47)$ & 27 & 41 \\
\hline East Midlands & $24.9(9.7)$ & $29.7(10.2)$ & $19(5)$ & 61 & 66 \\
\hline South East & $23.2(18.6)$ & 25.5 (20.9) & $10(12)$ & 41 & 52 \\
\hline East of England & $11.9(10.0)$ & $12.6(10.8)$ & $6(8)$ & 19 & 15 \\
\hline Yorkshire/Humber & $11.3(11.3)$ & $9.1(9.1)$ & $-19(-19)$ & 0 & 0 \\
\hline South West & $11.1(8.1)$ & $12.8(10.5)$ & $15(30)$ & 0 & 21 \\
\hline West Midlands & $10.4(10.4)$ & $25.8(12.5)$ & $148(20)$ & 16 & 38 \\
\hline North West & $9.8(8.3)$ & $12.0(10.5)$ & $22(27)$ & 0 & 25 \\
\hline All England & $17.2(12.6)$ & $23.0(15)$ & 34 (19) & 25 & 36 \\
\hline
\end{tabular}

CAMH, Child and adolescent mental health

1. Units that admit children and/or adolescents with a wide range of diagnoses and problems are categorised as 'general'.

2. English regions are based on boundaries set in 2003; the areas are ranked in order of the total beds per million total population in 1999 


\section{Discussion}

There has been much discussion about difficulties with original papers access to CAMH in-patient care in England during the period covered by these two surveys. The main indicator of the problem has been the high proportion of young people with mental disorder who are admitted to paediatric or adult psychiatric wards because no $\mathrm{CAMH}$ bed is available (Gowers et al, 2001; Mental Health Act Commission, 2001, 2004; Worrall et al, 2004).

Standard nine in the National Service Framework for Children, Young People and Maternity Services (Department of Health, 2004) places great emphasis on accessibility of services. In relation to CAMHS it requires that 'where a child or young person needs to be placed in an inpatient unit, every effort is made to find a place that is close to home, so that contact with the family can be maintained' (Department of Health, 2004: p. 19). The National Institute for Health and Clinical Excellence endorses this in its guideline for depression in children. This recommends that $\mathrm{CAMH}$ in-patient care should be available 'within reasonable travelling distance to enable the involvement of families and maintain social links' (National Collaborating Centre for Mental Health, 2005: p.165).

An even distribution of CAMH beds across the country is a prerequisite for optimal access. This survey shows that not only is provision very unevenly distributed but that the inequity has increased over the past 7 years. As a result, despite an overall increase in bed numbers, four regions of England are still well below the minimum of 20 beds per million population recommended by the Royal College of Psychiatrists (2006).

\section{The forces that have shaped the development of in-patient CAMHS}

The increasing inequity is perhaps an example of the effect of the incompatibility of different government policies on one type of specialised provision. Although a standard about access has been set centrally through the National Service Framework, responsibility for commissioning $\mathrm{CAMH}$ in-patient services, with the exception of forensic units and in-patient provision for deaf children, is devolved to a large number of primary care trusts that commission for a population of about 200000 . At the same time, the government has actively encouraged the independent sector to provide a larger proportion of NHS-funded care. The results of the survey would support the view that the force that is actually shaping $\mathrm{CAMH}$ in-patient services is not the National Service Framework but isolated decisions by commissioners about individual patients and the market's response to these. The problem is that the market response has resulted in a widening of the gap between areas with high levels of provision and those with low provision. The results of this study provide little evidence that primary care trusts have worked 'together as consortia to ensure that highly specialised (Tier 4) services are commissioned' or that 'strategic health authorities [have] oversee[n] and performance manage[d] collaborative commissioning arrangements' (Department of Health, 2004: p. 40).

\section{The future for in-patient services for children}

In contrast to services for adolescents, the number of beds available to children under the age of 14 has reduced markedly. During the period between the two surveys four units that admitted only children closed. Also, one general child and adolescent unit changed its admission policy and now admits only adolescents. At the time of writing, we are aware that one of the remaining children's unit was also under threat of closure.

\section{Conclusions}

Over the past 7 years an overall increase in $\mathrm{CAMH}$ bed numbers has been accompanied by increasing inequity of provision. We argue that the latter is partly the result of localised commissioning and increasing privatisation of this specialised resource. In-patient services for children under the age of 14 face an uncertain future.

\section{Declaration of interest}

None.

\section{References}

DEPARTMENT OF HEALTH (2002) Improvement, Expansion and Reform: The Next Three Years. Priorities and Planning Framework 2003-06. Department of Health.

DEPARTMENT OF HEALTH (2004) National Service Framework for Children, Young People and Maternity Services. Department of Health.

GOWERS, S. G., CLARKE, J., ALLDIS, M., et al (2001) In-patient admission of adolescents with mental disorder. Clinical Child Psychology and Psychiatry, 6, 537-544.

MENTALHEALTH ACT COMMISSION (2001) Ninth Biennial Report 19992001, ch. 6.43, p.73.TSO (The Stationery Office).

MENTAL HEALTH ACT COMMISSION (2004) Safeguarding Children and Adolescents Detained under the Mental Health Act 1983 on Adult Psychiatric Wards. TSO (The Stationery Office).

NATIONAL COLLABORATING CENTRE FOR MENTAL HEALTH (2005) Depression in Children and Young People: Identification and Management in Primary, Community and Secondary Care. British Psychological Society \& Royal College of Psychiatrists.

O'HERLHYY, A., WORRALL, A., LELLIOTT, P., et al (2003) Distribution and characteristics of in-patient child and adolescent mental health services in England and Wales. British Journal of Psychiatry, 183, 547-551.

ROYAL COLLEGE OF PSYCHIATRISTS (2006) Building and Sustaining Specialist Child and Adolescent Mental Health Services (Council Report CR137). Royal College of Psychiatrists.

WORRALL, A., O'HERLIHY, A., BANERJEE, S., et al (2004) Admissions of young people with a mental disorder to adult psychiatric and paediatric wards. BMJ, 328, 867 .

Anne O' Herlihy Research Fellow, Royal College of Psychiatrists' Research and Training Unit (CRTU), London, *Paul Lelliott Consultant Psychiatrist and Director of CRTU, 4th Floor, Standon House, 21 Mansell Street, London E1 8AA, email: p.lelliott@cru.rcpsych.ac.uk, Debbie Bannister Research Assistant, CRTU, London, Andrew Cotgrove Consultant Child and Adolescent Psychiatrist, CRTU, London, Hannah Farr Research Assistant, CRTU, London, Simon Tulloch Research Worker, CRTU, London 